The role of pre-treatment interpersonal problems for in-session emotional processing and long-term outcome in emotion-focused psychotherapy

\title{
Heinonen, Erkki
}

2020-07-03

Heinonen, E \& Pos , A E 2020 , ' The role of pre-treatment interpersonal problems for in-session emotional processing and long-term outcome in emotion-focused psychotherapy ' , Psychotherapy Research, vol. 30 , no. 5 , pp. 635-649 . https://doi.org/10.1080/10503307.2019.1630778

http://hdl.handle.net/10138/316308

https://doi.org/10.1080/10503307.2019.1630778

acceptedVersion

Downloaded from Helda, University of Helsinki institutional repository.

This is an electronic reprint of the original article.

This reprint may differ from the original in pagination and typographic detail.

Please cite the original version. 
The Role of Pre-Treatment Interpersonal Problems For In-Session Emotional Processing and Long-Term Outcome in Emotion-Focused Psychotherapy

\author{
Erkki Heinonen ${ }^{\mathrm{a}, \mathrm{b}, \mathrm{c}}$, Alberta E. Pos ${ }^{\mathrm{b}}$ \\ ${ }^{a}$ National Institute for Health and Welfare, Helsinki, Finland \\ bepartment of Psychology, York University, Toronto, ON, Canada \\ 'Department of Psychology and Logopedics, University of Helsinki, Finland
}

Address for correspondence: Erkki Heinonen, National Institute for Health and Welfare, Mannerheimintie 166b, P.O. Box 30, FIN-00271 Helsinki, Finland. Tel.: +358 29524 8774. Fax: +358 29524 8760. Email: erkki.heinonen@thl.fi

Acknowledgements: The first author acknowledges the financial support of the Foundations' Post Doc Pool. 


\begin{abstract}
Objective: Interpersonal problems may lead to, uphold, or follow from depression. However, we know little of how depressed patients' different interpersonal problems are associated with patients' emotional processing during psychotherapy and whether distinct processes are helpful for their long-term reduction.
\end{abstract}

Method: 23 adult outpatients who received emotion-focused therapies lasting 16-20 sessions filled the Inventory of Interpersonal Problems at pre- and post-treatment and 18-month followup. These problems were related to emotional processing in two mid-therapy sessions, rated by observers with the Classification of Affective-Meaning States.

Results: All pre-treatment interpersonal problems were clearly associated with patients' negative evaluations of themselves during therapy. Self-experiences of vindictiveness were most pronouncedly linked to in-session emotional expressions of rejecting anger, and self-experiences of social inhibition to expressions of fear and shame, following a circumplex model. In the longterm reduction of interpersonal problems, especially reaching emotional states of hurt and grief seemed beneficial for patients who experienced themselves as socially inhibited, non-assertive, self-sacrificing, or overly accommodating.

Conclusions: For clients suffering from particular interpersonal problems, accessing particularly beneficial emotional processes, such as hurt and grief, may form specific therapeutic process goals. Further studies should verify these findings, which link interpersonal theory with research on emotional processing in psychotherapy.

Keywords: depression; emotion in therapy; personality; interpersonal circumplex; outcome research; process research 


\section{Clinical and methodological significance of the article:}

Depressed patients' self-experienced interpersonal problems indicate which problematic emotions (e.g., fear, shame, or anger) they are likely to struggle with in therapy. Further, they indicate the types of emotional processing (e.g., hurt, grief, or assertive anger) which may be particularly beneficial for reducing those problems. As such, the findings may help clinicians to develop treatment strategies to address the particular needs of different clients, and more individualized treatment of depression. 


\section{Introduction}

Interpersonal problems may lead to, maintain, as well as follow from depression (Hames, Hagan, \& Joiner, 2013). Although different psychotherapies have been empirically established as effective treatments for major depressive disorder (MDD) (Barth et al., 2016; Cuijpers et al., 2014), less is known about how effectively these treatments ameliorate interpersonal problems (McFarquhar, Luyten, \& Fonagy, 2018). Nevertheless, given their frequently close connection with depression (Barrett \& Barber, 2007; Cain et al., 2012; Dinger et al., 2015), improvement in the interpersonal domain can arguably facilitate both a more thorough as well as longer-lasting and resilient recovery from MDD (Hames et al., 2013; Horowitz, 2004). Considering the interpersonal problems of depressed patients may, however, make another important contribution to treatment: shedding light on what particular patients struggle with and what is curative for them, thereby helping improve the effectiveness of psychotherapeutic interventions.

A long line of interpersonal theory and research, originating from Sullivan's (1953) and Leary's (1957) work (cf. Pincus \& Ansell, 2003), suggests individuals differ in both health and pathology on two interpersonal dimensions: in their need for 1) agency (i.e., for autonomy, individualism, and control), and for 2) affiliation (i.e., to connect with others, be loved, and belong) (e.g., Bakan, 1966; Horowitz, 2004). A patient's interpersonal problems, as well as psychiatric syndromes such as depression, may be understood in terms of frustrations of these needs. For instance, losing a job is a prototypically 'agentic' loss, whereas losing an important relationship is a prototypically 'affiliative' loss, from which depression may follow. Importantly, different individuals may be particularly vulnerable to losses on either the agentic or the affiliative dimension (Horowitz, 2004; O’Brien \& DeLongis, 1996). 
Indeed, several major psychotherapeutic approaches have articulated subtypes of depression depending on which of the two main dimensions has particular salience for an individual, although different terms have been employed by different theorists: 'introjective' versus 'anaclitic' depression in psychodynamic therapy (Blatt, Shahar, \& Zuroff, 2001; Blatt \& Shahar, 2004; Blatt \& Zuroff, 1992), 'autonomous' versus 'sociotropic' types in cognitive therapy (Beck, 1983), or 'bad self' versus 'weak self' depressive dilemmas in emotion-focused therapy (Whelton \& Greenberg, 2005). The complex phenomenology of depression - with its intertwined emotions, thoughts, and bodily and behavioral concomitants - has been seen to differ for these subtypes but centering on experiences of defeat and self-blame for the former, agencyrelated group, and loneliness and isolation for the latter, affiliation-related group (Barrett \& Barber, 2007; Desmet et al., 2007; Dinger et al., 2014).

It nevertheless should be recognized that the agentic and affiliative needs (or frustrations) do not exclude each other, but rather form a circumplex. An individual's standing on both these dimensions is seen to impact his or her likely relational manner and interpersonal problems and, plausibly, his or her experience of depression. Fortunately, a psychometrically valid and reliable self-report instrument for assessing these two dimensions in a transtheoretical framework has been created with the Inventory of Interpersonal Problems (IIP) (Figure 1) (Horowitz, Alden, Wiggins, \& Pincus, 2000). For instance, an individual with low agentic and high affiliative needs would typically yield to others and be highly motivated to maintain relationships (Wang et al., 2014). Such an 'overly accommodating' person might be vulnerable to being used and abused by others. Especially when depressed, such an individual might plausibly feel sad about not being able to express his or her needs or get them met, while also fearing others to leave him or her. In such ways, interpersonal problems and subtypes of clinical syndromes such as depression can 
intertwine with self- and other-related emotions, cognitions, and behavior (Widiger \& Smith, 2008). To the extent these emotions, cognitions, or behavior relate to the dimensions of agency and affiliation, they may also follow a circumplex structure (Gurtman, 1992; Zimmermann \& Wright, 2017).

Although different patterns of interpersonal problems can be distinguished in depressed populations (Barrett \& Barber, 2007; Dinger et al., 2014; Horowitz et al., 2000), it is less clear whether different therapeutic processes are effective for ameliorating them. The little extant research has mostly compared different treatments for the aforementioned two subtypes of depression differing on the dimensions of agency and affiliation, e.g., 'anaclitic' vs. 'introjective' (Blatt et al., 2001, 2004), indicating some promise for such differentiation: showing expectedly, for instance, that dependent patients (i.e., with more affiliative concerns) fared better in a more supportive, face-to-face psychodynamic therapy form, whereas patients with a high need for autonomy (i.e., with more agentic concerns) fared better in psychoanalysis (i.e., with a relatively abstinent therapist) (Blatt et al., 2001, 2004; see also Werbart et al., in press). However, the close-up processes of psychotherapeutic change have still been little explored for patients suffering from varying interpersonal problems and the possible combinations of agentic and affiliative concerns.

\section{The importance of emotional processing for psychotherapeutic change}

Different therapy modalities aim for change in different ways: through modification of thoughts in cognitive therapy, increase of insight in psychodynamic treatment, or exposure to feared situations in behavioral therapy, for instance. However, it has been recognized that emotional arousal and processing may be a crucial component across approaches to effect profound change (Frank \& Frank, 1991; Lane, Ryan, Nadel \& Greenberg, 2015; Pascual-Leone, 
2018; Teasdale, 1999). This might be particularly important in interpersonal problems, which often reflect rigid patterns of behaving, thinking, and feeling learned early in life and over a long period of time (Hames et al., 2013; Heinonen, Knekt, Harkanen, Virtala, \& Lindfors, 2018; Horowitz, 2004), and are more resistant to change than depressive symptoms or overall morale (Barkham, 1996; Grosse Holtforth et al., 2019; Haase et al., 2008).

Support for the importance of emotional processing for ameliorating interpersonal problems also exists. A recent review and meta-analysis indicated that emotion-focused therapy (EFT), an approach that works to help clients affectively transform problematic emotion states, was particularly effective in improving interpersonal problems as compared to a number of other therapy approaches (McFarquhar et al., 2018). Also, earlier direct comparisons in randomized trials have shown EFT to be more effective for interpersonal problems than cognitive-behavioral therapy as measured at post-treatment (Watson, Gordon, Stermac, Kalogerakos, \& Steckley, 2003) and client-centered therapy at 18 months' follow-up (Ellison, Greenberg, Goldman, \& Angus, 2009).

The specific emotional processing mechanisms for these effects have yet to be identified. Still, this may partly result because the specific tasks in EFT (Greenberg, 2002), such as chair work, are highly interpersonal in nature (Pos \& Paolone, in press). That is, they often promote imagined dialogues between the self and another (e.g., between oneself and one's parent), as in empty chair work; or, as in two-chair work, between different aspects of the self (e.g., between a hopeless self and a judgmental or critical part of the self), which frequently reflect early internalizations of significant others as well as influence present-day interactions (e.g., Benjamin, 1974). For that reason, EFT may be effective at accessing and transforming painful interpersonal affect, and at facilitating recovery from the interpersonal dysfunction underpinning 
depression. It may also be noted that emotions themselves are often essentially interpersonal: that is, a person fears or resents someone, is ashamed of oneself in the (imagined) eyes of others, and so on (cf., Kiesler, Schmidt \& Wagner, 1997). Yet the role of different emotional processing states in the amelioration of particular interpersonal problems remains unexplored. More specifically: Are different types of emotional processes involved and beneficial in ameliorating different interpersonal problems?

Given that different interpersonal problems, and the related depressive subtypes (as described above), often relate to patients being either overly prone to - or being unable or unwilling to - experience or express specific emotional states (Blatt et al., 2001; Greenberg, 2004; Grosse Holtforth, Pincus, Grawe, Mauler, \& Castonguay, 2007; Horowitz, 2004; Timulak \& Pascual-Leone, 2015), this seems plausible. Both research and clinical experience suggests patients who are low on agency - e.g., socially inhibited, non-assertive and dependent clients might have difficulty feeling or expressing anger but may not avoid acknowledging feelings related to fear or shame (Blatt et al, 2001; Sadikaj, Moskowitz, Russell, \& Zuroff, 2015; Wang et al., 2014). In turn, patients with high agentic concerns - e.g., domineering, narcissistic/vindictive, intrusive - might find vulnerable feelings of fear, hurt, grief, and loss threatening to their image of self-sufficiency, and be prone instead to expressing anger (Blatt \& Shahar, 2004; Pincus, Cain, \& Wright, 2014; Roche, Pincus, Lukowitsky, Ménard, \& Conroy, 2013). Especially vindictive tendencies might most likely manifest in therapy as rejecting anger or narcissistic rage (cf. Pascual-Leone \& Greenberg, 2005), which can be seen to exhibit both agency and a desire to disaffiliate. In turn, fear and shame might be most characteristic for socially inhibited patients, who experience both helplessness (low agency) and a desire to avoid embarrassment (low affiliation) (Horowitz, 2004). Yet other experiences, such as negative self- 
evaluation - reflecting self-appraised failure in either the agentic or affiliative dimension (cf. Pascual-Leone \& Greenberg, 2005) - would be expectably demonstrated in therapy by patients suffering from any interpersonal problems (Pincus et al., 2014).

To put it differently: the interpersonal problems of patients might predispose them to expressing some general complaints but also some specific difficult or maladaptive emotions during treatment which are particular to those interpersonal problems (Hopwood, Zimmermann, Pincus, \& Krueger, 2015) - especially in a treatment such as EFT that often amplifies these emotions to work through them (Greenberg \& Paivio, 1997; Greenberg, Rice, \& Elliott, 1993). Conversely, it might be particularly therapeutic for these patients to access and express the types of adaptive emotions that are less typical for their personality configuration: i.e., the validity of one's own needs and assertive anger to defend them, in the case of the less agentic patients and the overly accommodating type in particular; and, in the case of the patients for whom seeing themselves as agentic is important, the vindictive type in particular, reaching feelings of vulnerability and compassion toward the self (Greenberg, 2004; Horowitz, 2004; Lane et al., 2015; Pascual-Leone \& Greenberg, 2005).

While therapeutic modalities of many types see such affectively charged new selfexperiences as transformative (Lane et al., 2015), there is still little systematic empirical research on their significance in ameliorating different interpersonal problems. The above-mentioned hypotheses were therefore investigated in a group of 23 depressed adult clients who had received short-term EFT (16-20 sessions) in the York I or II research trials on experiential treatments of depression (Goldman, Greenberg, \& Angus, 2006; Greenberg \& Watson, 1998). The questions were explored in the clients' most helpful sessions, as determined by their post-session ratings. Given the model of therapeutic change in EFT - i.e., accessing maladaptive emotions together 
with adaptive emotions to effect change - we expected both maladaptive and adaptive emotion states to be expressed in these sessions (Pascual-Leone, 2009). The above-mentioned hypotheses are summarized below.

\section{Hypotheses}

\section{Hypothesis 1: Maladaptive emotions:}

Hypothesis 1.1: Self-rated interpersonal problems that relate to being overly agentic (i.e., domineering, vindictive, or intrusive) are associated with more in-session expressions of rejecting anger, being most strongly associated with vindictiveness.

Hypothesis 1.2. Self-rated interpersonal problems that relate to being non-agentic (i.e., socially inhibited, non-assertive, or too accommodating) conversely are associated with more in-session expressions of fear and shame, being most strongly associated with social inhibition.

Hypothesis 1.3. All self-rated interpersonal problems are expected to be associated with more insession expressions of negative self-evaluation.

Hypothesis 2: Adaptive emotions:

Hypothesis 2.1.: Emotional processing states of hurt, grief, and self-soothing are associated with improvement in interpersonal problems that relate to being overly agentic, particularly vindictiveness.

Hypothesis 2.2.: Emotional processing states of expressing one's own needs and assertive anger are associated with improvement in interpersonal problems that relate to being non-agentic, particularly the experience of being overly accommodating.

\section{Method}


The data for the present study was collected between 1992 and 1999 as part of the York I (Greenberg \& Watson, 1998) and York II (Goldman et al., 2006) Depression Studies. These two randomized clinical trials tested the effectiveness of two experiential psychotherapies for treating MDD, client-centered therapy (CC) and emotion-focused therapy (EFT). Due to EFT having been shown to effectively address interpersonal problems (Ellison et al., 2009; McFarquhar et al., 2018; Watson et al., 2003) and its specific focus on emotion, the present study exclusively utilized data of patients who underwent EFT.

\section{Patients}

Participants were recruited via radio and newspaper advertisements in the greater Toronto metropolitan area, via local advertisement at York University, and from the pool of treatmentseekers at the university clinic. Eligible clients met criteria for MDD on the Structured Clinical Interview (SCID) (Spitzer, Williams, Gibon, \& First, 1989) of the DSM-III-R (American Psychiatric Association, 1987). Exclusion criteria were being psychotic, having bipolar, antisocial or borderline personality disorders, or having an eating, drug, or alcohol abuse disorder; a history of incest; having engaged in recent suicide attempts; having recently lost a significant other in the past year; or being involved in an ongoing violent relationship. The clients' Global Assessment and Functioning Scale (GAF) score also could not be lower than 50.

Eligible patients who gave written informed consent were randomized into $\mathrm{CC}$ and EFT and followed up for 18 months post-treatment. The present study is based on the 23 clients who were randomized to and participated in EFT and provided both post-treatment and 18-month outcomes on their IIP domain scores.

\section{Treatments}


EFT is an experiential therapy integrating client-centered and gestalt therapy with current emotion theory (Greenberg et al., 1993; Greenberg \& Watson, 2006). In the first three sessions, therapists exclusively provide client-centered facilitative relationship conditions, such as unconditional positive regard, empathy, and congruence. They follow the clients' internal track, communicate empathy, facilitate exploration, encourage symbolization of core meaning, and increase emotional awareness. Thereafter, therapists engage in marker-guided, process-directive, empirically supported interventions derived from gestalt and experiential therapy (Greenberg \& Watson, 2006). These include two-chair dialogue for self-evaluative conflict; empty-chair dialogue for unfinished business with a significant other; focusing on an unclear felt sense; and systematic evocative unfolding for problematic reactions.

The aim of treatment is emotional transformation, i.e., to change distressing emotions with emotion (Greenberg, 2004). Within EFT, when patients come into therapy, their emotions are typically seen and thought to reflect secondary maladaptive emotions - e.g., hopelessness, rejecting anger, or helplessness - that shield one from experiencing more painful primary maladaptive emotions - e.g., deep worthlessness, abandonment, or loneliness (Greenberg \& Paivio, 1997). In therapeutic interventions (such as chair work), these deeper maladaptive feelings and their related negative self-evaluations are then accessed, and the needs associated with them - e.g., for freedom, love, or protection - are evoked, and brought in contact with more adaptive primary emotions, such as grief over a loss or assertive anger to protect oneself. Attending to and validating the adaptive emotions and making sense of them is then used to vitalize a more resilient sense of self to transform the person's maladaptive affects, explicitly challenge maladaptive beliefs, and consolidate new self-organization and self-experience (Greenberg, 2004). 
The described adaptive and maladaptive emotional processes in EFT have been operationalized with the Classification of Affective Meaning States (CAMS), described below (Pascual-Leone, 2005, 2018). Studies utilizing CAMS have shown support for several aspects of the hypothesized model of psychotherapeutic change in EFT, across a number of psychiatric disorders and even other therapeutic approaches (Pascual-Leone, 2018).

\section{Therapists}

A total of 16 therapists provided EFT. Prior to training, therapists had all received at least one year of prior training in EFT, and received an additional 48 hours of training, two hours weekly for 24 weeks, before the commencement of either project. Training involved didactic instruction, viewing videos, live demonstrations, and in-vivo practice in dyads. All therapists were supervised by licensed psychologists on a weekly basis. All treatments were monitored through audio and videotape for adherence (Greenberg \& Watson, 1998). Treatments were judged as adhering to treatment on the same adherence criteria (Greenberg \& Watson, 1998).

\section{Measures}

\section{Assessment of interpersonal problems.}

The Inventory of Interpersonal Problems (IIP) (Horowitz et al., 2000) is a 64-item self-report instrument that assesses difficulties in interpersonal functioning in eight different domains, each measured by eight items, across two dimensions representing affiliation (friendly-unfriendly) and agency (dominant-submissive) (Figure 1). The questions are of two forms: "It is hard for me to..." (39 items) or "I do... too much." (25 items). Each item is rated on a 5-point Likert scale, ranging from 0 (not at all) to 4 (very much). The eight octant scores are each based on a sum score of their respective eight items. Their theoretical range is thus 0 to 32 and, for the total 
scale, 0 to 256. A representative sample $(n=200)$ drawn from the U.S. non-clinical population, and most closely approximating the age range (i.e., 25-44 yrs.) of patients in the present study, indicated comparatively lower prevalence of self-reported problems involving higher agency i.e. experiencing oneself as Dominant/Controlling ( $M=4.8, S D=4.5)$, Vindictive/Self-Centered $(\mathrm{M}=5.1, \mathrm{SD}=4.9)$, or Intrusive/Needy $(\mathrm{M}=5.1, \mathrm{SD}=5.6)$ - or purely low affiliation (i.e., experiencing oneself as Cold/Distant, $\mathrm{M}=5.1, \mathrm{SD}=5.6$ ); and slightly higher prevalence of selfreported interpersonal problems involving lower agency - i.e., experiencing oneself as Socially Inhibited ( $\mathrm{M}=6.7, \mathrm{SD}=6.1)$, Nonassertive $(\mathrm{M}=7.6, \mathrm{SD}=6.3)$, Overly Accommodating $(\mathrm{M}=7.6$, $\mathrm{SD}=5.5$ ) - or purely high affiliation (i.e., experiencing oneself as Self-Sacrificing, $\mathrm{M}=7.9$, $\mathrm{SD}=5.7$ ) (Horowitz et al., 2000). In this normative sample, the total sum of self-rated interpersonal problems across all subscales was $50.5(\mathrm{SD}=35.7)$. Test-retest reliability for these scales has been reported between .89 to .98 , with internal consistency ranging from .89 to .94 (Cronbach alphas) (Horowitz, Rosenberg, Baer, Ureno, \& Villasenor, 1988). In the current York I and II Depression Study data, the reliability of the eight scales ranged from .69 to .88 (Cronbach alphas), thus being generally in the 'acceptable' to 'good' range.

\section{Assessment of emotional processing states.}

The Classification of Affective Meaning States (CAMS) (Pascual-Leone \& Greenberg, 2005) was created to identify discrete, specific states expressed during emotional processing in psychotherapy. The measure can be used to code events during which participants are emotionally involved and aroused: that is, where participants are not explicitly avoiding or interrupting emotional reporting. The categories are differentiated from each other by distinctions in emotional tone; involvement or arousal; and meaning-making or cognitive processing. 
The different CAMS categories, relevant to the hypotheses of the present study, are: (i) rejecting anger which captures clients' expression of distancing and destructive anger; (ii) fear/shame which captures core feelings of inadequacy, worthlessness, and fear; (iii) negative self-evaluation which captures clients' core articulated judgment of themselves (e.g., 'I don't have what it takes"); iv) needs, capturing expression of personal and universal needs (e.g., for autonomy, affection, support, etc.) that have often not been met; (vi) hurt/grief which captures clients' core experiences of sadness, loss, and pain; (vii) assertive anger which captures adaptive anger that supports setting appropriate boundaries; and (vii) self-soothing which captures clients' expressions of self-compassion and self-nurturance. The scales have been more thoroughly described by Pascual-Leone and Greenberg $(2005,2007)$ and Pascual-Leone $(2009,2018)$.

Of these categories, i)-iii) are generally considered to be maladaptive, in that they are aversive states in which the patient typically gets "stuck in" and wants to get rid of. The latter four are considered adaptive emotion states because even though they may involve pain, they are assumed to facilitate movement towards empowerment, acceptance, and recovery (PascualLeone, 2009, 2018). For the purposes of the present study, it is worthwhile to recognize that while some of these emotion states (for instance, hurt and grief) may share some similarity with features of MDD such as depressed mood, the CAMS states reflect distinct, discrete, aroused emotional processing states evidenced during therapy, as opposed to (for instance) the persistent low mood characteristic of MDD.

Prior studies have established, with two raters, that CAMS can be rated reliably as per when a change in emotional processing state occurs (85.9\% agreement); the sequential ordering of the specific emotional processing states (Cohen's $\mathrm{k}=0.91$ ); and how long a given emotional 
processing state lasts $(r=.76)$, thus demonstrating the overall high reliability of CAMS (PascualLeone \& Greenberg, 2005).

\section{Assessment of depression.}

The Beck Depression Inventory (BDI) is a 21-item self-report inventory measuring depressive symptoms (Beck, 1961). Each item has four response alternatives. A review of empirical studies has shown the BDI to have good internal consistency (coefficient alphas 0.76-0.95, with a mean reliability of 0.86 , across a range of ten psychiatric populations) as well as discriminant and concurrent validity (Beck, Steer, \& Garbin, 1988).

\section{Assessment of session quality.}

Three self-rated session measures were administered to patients after every session throughout treatment: 1) General Session Evaluation Questionnaire (GSEQ) (Orlinsky \& Howard, 1975), 2) Helpful Aspects of Therapy Form (HAT) (Elliot, Slatick, \& Urman, 2001; Llewelyn, 1988), and

3) Client Task Specific Measure (CTSM) (Greenberg \& Safran, 1991, 1993). These three measures assess, respectively, 1) clients' overall evaluation of the session and to what degree something changed or shifted for them, and the degree to which they feel they would take a different course of action as its result; 2) perceptions of significant therapy events; and 3) progress on the main tasks of treatment.

\section{Session sampling}

For all clients who had provided 18-month follow-up data, two sessions were selected from the working phase of therapy, i.e., between the fourth and the fourth-last session. The sessions chosen had been identified by the clients as their most productive, based on post-session evaluation questionnaires, according to the following criteria: 1) they reported on the GSEQ the 
highest degree of shift or change as a result of these sessions; 2) clients rated these on the HAT as the sessions resulting in the most felt progress; and 3) they reported on the CTSM measure the highest degree of task resolution. If these measures were discrepant, priority was given to session outcome criteria 1 and 3. In the case that more than two mid-therapy sessions were equivalent on these two criteria, a tie-breaking discrimination was made with the therapist report on the session's productiveness (TSR) (unpublished questionnaire), assessing therapist's view on whether the client had, e.g., experienced a significant shift in perception or feeling or resolved a core issue in the session. If more than two sessions still appeared equally productive, the two earliest productive mid-therapy sessions, most distant from the late sessions (i.e., from the last four sessions), were selected (Pos, 2006).

\section{Session coding}

After identification of the two most helpful sessions, three independent raters reliably identified emotion episodes (EE) within these sessions. EEs are session narratives in which the client expresses a past or present emotional experience (Korman, 1991; Pos, 2006). They are identified by an antecedent situation or stimulus and either an emotional response (e.g., "I'm sad") or an expressed action tendency associated with that emotional response (e.g., crying). These EEs were then reliably coded for emotional processing states with the CAMS by two raters, each EE receiving one CAMS code. The proportion of each CAMS category out of the total proportion of CAMS categories was then calculated, collapsing the measures from the two most helpful sessions. Using two sessions was chosen to ensure a more reliable and sensitive detection of potential effects than enabled by assessing only one session. CAMS raters had been trained for the method by the measure's developer, Dr. Pascual-Leone, during three training sessions (25 hrs. in total). All CAMS coding was carried out independently and blind to outcome. 
Independent ratings from the two coders were used for reliability analysis and consensus ratings were obtained for any disagreements. If a consensus could not be reached on a particular rating, an expert CAMS code was provided by Dr. Pascual-Leone. Reliability and Cohen's Kappa for CAMS ratings in this dataset had been found to be .80 , indicating excellent inter-rater reliability (Choi, Pos, \& Magnusson, 2016; Wong, 2016).

\section{Statistical methods}

To examine the first hypothesis, Pearson's $r$ correlations were calculated to examine the relationships among patient-rated pre-treatment interpersonal problems (IIP) and observer-rated emotional processing states (CAMS) in the selected therapy sessions. Based on the correlations, the Structural Summary Method (SSM) (Gurtman, 1992; Gurtman \& Pincus, 2003) was then used to evaluate the fit of the CAMS categories evidenced during the sessions to the circumplex model of interpersonal problem space, and calculate their respective elevations, amplitudes, and angles. Elevation represents the average correlation of the CAMS category across all IIP octants, i.e., its association with general interpersonal distress. The amplitude refers, in turn, to how differentiated the profile is, i.e., the distinctness of the interpersonal content of the CAMS category. The angle indicates where the predominant content of the CAMS category is located on the interpersonal problem space. Finally, goodness of fit index, $\mathrm{R}^{2}$, informs about the fit of the observed pattern of correlations to the circumplex structure. Values $>.15$ for elevation and amplitude have been considered to indicate a markedly elevated and differentiated profile, whereas values $>.80$ indicate a good fit (values $>.70$ being acceptable) with the circumplex structure (Gurtman \& Pincus, 2003; Wright et al., 2012; Zimmermann \& Wright, 2017). Thus, these parameters answer to whether CAMS categories are associated with general interpersonal distress and/or a specific interpersonal style. 
Severity of depressive symptoms (BDI) was examined as a potential confounder between pre-treatment interpersonal problems and emotional processing states. However, it was not associated with either to the extent to satisfy the conventional criteria for confounding $(p<.20)$ (Rothman, Greenland \& Lash, 2008; Skzlo \& Nieto, 2014), and consequently not included in the models.

To examine the second hypothesis, residual gain scores were first calculated for reported change in patients' self-rated interpersonal problems from pre-treatment to post-treatment and also from pre-treatment to 18-month follow-up. Hence, negative residual gain scores indicated reductions in a particular IIP domain not predictable from the initial baseline alone. Pearson's $r$ correlations were then calculated to examine the relationship among emotional processing states in helpful sessions of therapy and the patients' residual gain scores at termination and follow-up.

Due to the small sample size and the partially exploratory nature of the study, all associations with a significance level of $p<.10$ are reported and discussed. Although $p$ values above .05 are often considered non-significant due to their potential unreliability, we decided to err on the side of not committing Type II errors which stifle new research arenas (Streiner \& Norman, 2011), by considering both the size of any reported result and its $p$ value. Therefore, we chose to report any correlation that had at least a large sized effect (Pearson's $r=.30$ ) (Becker, 2000) and whose $p$ value was under .10 .

\section{Results}

\section{Descriptive baseline results}

Patient mean age was approximately 40 years and $61 \%$ were female (Table 1 ). Approximately two thirds had completed college or higher education, and one third had never 
married. Information on ethnicity was not systematically collected. However, its diversity is believed to be representative of a large, multicultural urban area.

\section{Descriptive in-session results}

During the sessions, the most prevalently expressed maladaptive emotional processing state was Fear/Shame, Rejecting Anger being the second most prevalent (Table 2). The most prevalent adaptive emotional processing state was the expression of Needs, with Assertive Anger and Hurt/Grief being the second and third most prevalent.

\section{Descriptive results from pre- to post-treatment and 18 months' follow-up}

Most prevalent self-reported problems related to experiencing oneself as non-assertive or self-sacrificing. The interpersonal problems that changed the most were related to experiencing oneself as non-assertive, socially inhibited, or self-sacrificing (Table 3). Similar changes, albeit slightly attenuated from those at post-treatment, were reported at 18 months' follow-up. Change was statistically significant across the three different time points for the majority of the subscales.

\section{Hypotheses 1: The association of pre-treatment interpersonal problems with emotional processing states in therapy}

Statistically significant relationships were found between patients' pre-treatment reports of interpersonal problems and their expressions of emotional states during their most helpful therapy sessions (Table 4). Most conspicuously, higher scores on all domains of interpersonal problems were associated with more Negative Self-Evaluation during therapy. Pre-treatment reports of experiencing oneself as socially inhibited was associated with more expressions of Fear/Shame during treatment. When reproducing the pattern of correlations with the SSM, the 
amplitudes of both Rejecting Anger (.24) and Fear/Shame (.31) indicated interpersonal specificity of these emotional processing states and a 'good' fit with the circumplex model (.91 and .82, respectively), peaking between Dominant and Vindictive $\left(91.6^{\circ}\right)$ and Socially inhibited and Nonassertive $\left(242.6^{\circ}\right)$ octants, respectively. Thus, the SSM parameters provide a good summary of the observed correlations. As the goodness of fit was below .7 for Negative SelfEvaluation, we did not compute amplitude and angle, as these cannot be reliably interpreted.

\section{Hypothesis 2: The associations of emotional processing states with reductions in interpersonal problems at post-treatment and 18-month follow-up}

Only two statistically significant associations were found between in-therapy expression of emotional processing states and the pre-post-therapy change in interpersonal problems. Expression of one's Needs was associated with reductions in self-experiences of being dominant $(\mathrm{r}=-.44, \mathrm{p}=.03)$ and vindictive $(\mathrm{r}=-.39, \mathrm{p}=.05)$, as measured at treatment termination.

Expression of Assertive Anger was associated with reduction of reporting oneself specifically as self-sacrificing or dominant, as measured at 18-month follow-up, as well as reduction of overall interpersonal problems. (Table 5). Expression of Hurt/Grief was associated with reduction in reporting oneself as socially inhibited, non-assertive, overly accommodating, or self-sacrificing at 18 -month follow-up. Self-Soothing was associated with reduction of reporting oneself as overly accommodating.

\section{Discussion}

This study was guided by two research questions: First, whether different pre-treatment interpersonal problems predict specific expressions of maladaptive emotional states in psychotherapeutic sessions. Secondly, whether different adaptive emotional processes are helpful 
for reducing interpersonal issues, as evidenced immediately at post-treatment and at 18-month follow-up.

Before examining our hypotheses, we first note that the total change in interpersonal problems from pre- to post-treatment reflected an effect size between 'medium' and 'large' (Cohen's $d=0.66$ ), comparable to the overall effect size yielded by a recent meta-analysis across different types of brief psychotherapies (McFarquhar et al, 2016). However, whereas the few studies on interpersonal problems with a follow-up have generally seen outcomes to attenuate over time, our results remained quite stable at the 18-month follow-up $(d=0.63)$. In line with other studies examining the different subdomains of interpersonal problems (Grosse Holtforth et al., 2006; Huber et al., 2007; Leichsenring, Biskup, Kreische, \& Staats, 2005), also in our study the most prevalent self-rated interpersonal problems were in the less agentic and/or more affiliative dimensions: i.e., experiencing oneself as socially inhibited, non-assertive, overly accommodating, or self-sacrificing - these subdomains also being those that generally evidenced the most change.

As for our specific hypotheses, our two broad hypotheses were met with support as well as some unexpected findings. Our results, discussed below, thereby provide initial empirical evidence and impetus for further studies on emotional processes related to different interpersonal issues and their reduction in psychotherapy.

\section{Hypothesis 1: Maladaptive emotions}

Our first hypothesis was that pre-treatment interpersonal problems of experiencing oneself as overly agentic (i.e., domineering, vindictive, or intrusive) would be associated with more in-session expressions of rejecting anger (especially vindictiveness). Conversely, we 
expected that pre-treatment problems that relate to being non-agentic (i.e., socially inhibited, non-assertive, or too accommodating) would be associated with more expressions of fear and shame (especially social inhibition). Finally, all interpersonal problems were expected to be associated with negative self-evaluation.

This hypothesis received considerable support. The three overly 'agentic' domains were the only ones positively associated with in-session rejecting anger - vindictiveness most of all, as hypothesized. In turn, the three less 'agentic' domains were more strongly associated with fear and shame - social inhibition most strongly, as hypothesized. The pattern of correlations fit a circumplex to a 'good' degree, supporting the hypothesis of the 'localization' of these maladaptive emotional processing states in the interpersonal problem space.

Patients' pre-treatment self-ratings of interpersonal problems thus appear to be logically associated with the types of problematic emotional states expressed during therapy; at least in EFT, which accesses and even purposefully amplifies (e.g., through chair work) maladaptive emotions in the aim of transforming them (Elliott et al., 2004). Thus, a vindictive patient may have been encouraged in EFT to express intense anger toward his or her parents. A socially inhibited patient might have been encouraged to make him- or herself scared and ashamed by assuming the position of his or her internal critic. However, given these emotional expressions were rated in what patients considered also to be their most productive sessions, what is suggested is that patients found these emotional experiences helpful. For instance, by connecting to their core shame and fear, socially inhibited patients may have gained an important connection to what and why they hide from others. As such, the present findings provide support for the EFT rationale that in order to resolve problematic emotions, they first need to be allowed and attended to (Greenberg, 2004) or that "the only way out is through" (Pascual-Leone \& 
Greenberg, 2007) - at least in these patients' experience. We do not know whether (or which) particular interpersonal issues were worked on during these sessions. However, the emergence of these expected associations, despite this static, speaks to the robustness of the connections between emotions and how patients see themselves and act in relation to others.

Finally, we observed that unlike Rejecting Anger and Fear/Shame, Negative SelfEvaluation was positively associated with all self-rated interpersonal problems, its elevation also being notably high. This may not be surprising, since interpersonal problems are gauged in the IIP via statements which are negative endorsements of the self (i.e. "It is hard for me to..." and "[Things that I do] too much..."). Therefore, endorsement of essentially all IIP items would logically be related to more negative cognitions regarding the self, which expectably might be expressed during therapy (Thompson, D’iuso, Schwartzman, Dobson, \& Drapeau, 2018). It has also been recognized that even narcissistic patients - who otherwise typically devalue others rather than themselves - are likely to enter treatment in a vulnerable self-state and thus more likely exhibiting self-criticism (Pincus et al., 2014). Our finding nevertheless suggests that for developing therapeutic interventions, future research which we aim to undertake should parse the content of these self-evaluations more closely: What are the contents of patients' negative selfevaluations and do they cohere with different interpersonal problems? Negative self-evaluations may mark arrival at one's "core pain" and the readiness to work with these issues, and therefore be important intervention points for the clinician (Elliott et al., 2004).

\section{Hypothesis 2: Reducing interpersonal problems through accessing adaptive emotional} states 
Our second hypothesis was that reduction of interpersonal problems would more likely be achieved by patients who could access and experience emotions presumably less characteristic for them. Mixed support was obtained for expectation.

Relatively few significant findings were seen immediately at post-treatment. Significant associations were seen, however, between in-session expression of one's needs and improvement on the dominant and vindictive subdomains at treatment termination. Although not the relationship we originally hypothesized, this association may nevertheless be taken to support the gist of our hypothesis: given these problem subdomains are characterized by desire for control, self-sufficiency, and/or hostility, expressing needs might have been a particularly difficult expression of vulnerability for these clients.

However, it was not the emotional processing states implying vulnerability - such as hurt/grief and self-soothing - which we saw associated with improvement at follow-up in the overly agentic (i.e., domineering, intrusive, vindictive) domain. Instead, we saw a significant association between in-session assertive anger and improvement on the dominant subdomain. Why? We would surmise that at least for some of these clients, what occurred was a transformation of rejecting (i.e., maladaptive) anger to assertive (i.e., adaptive) anger. This is empirically supported by dominant patients more often expressing rejecting anger (cf. Hypothesis 1), but only assertive anger predicting better long-term outcomes. This is theoretically and clinically plausible as well. If reporting oneself (pre-treatment) to be problematically domineering points to frustration of personal needs by others, this may lead to these patients expressing rejecting anger toward others (Elliott et al., 2004; Horowitz, 2004). When these clients' needs are validated in EFT, these clients may more comfortably express, assert, and stand up for their needs, thus ameliorating self-experiences of being problematically 
dominant (Pascual-Leone \& Greenberg, 2005). This change would be consonant with a transformation of rejecting anger into assertive anger (Elliott et al., 2004). This interpretation might be more fully explored by investigating emotional processing sequences extending from the early until the ending states of treatment, which we aim to pursue in further research.

In problems relating to low agency, we saw assertive anger also associated with improvement on the self-sacrificing domain - relatively close, in terms of the interpersonal circumplex, to our original hypothesis of it being helpful especially for non-assertiveness. Prior research has shown that cognitive-behaviorally oriented assertiveness training - i.e., learning behavioral skills and restructuring anxious thoughts - can improve relationship satisfaction (Speed, Goldstein, \& Goldfried, 2017). However, the present results suggest similar ends can be achieved by the more experientially oriented interventions of EFT. Nevertheless, it is not known how this self-experienced improvement would correlate with changes in patients' relational behavior outside of therapy.

Otherwise, our hypothesis that improvement specifically on the less agentic (e.g., nonassertive, socially inhibited, overly accommodating) problem domains would be associated specifically with reaching more agentic emotions such as assertive anger was not supported. Instead, hurt/grief was associated with improvement on them as well as the self-sacrificing subdomain at follow-up. Although not exactly the relationship we hypothesized, we consider that reaching hurt and grief may nevertheless have facilitated a patient's shift into a more agentic self-organization. In feeling oneself problematically non-assertive, socially inhibited, or accommodating, the problem focus is external - on behavior with others. However, what appeared curative for these patients seemed instead to be reaching the deep internal focus that hurt/grief marks: what has been personally meaningful yet lost (Pascual-Leone \& Greenberg, 
2005). It is nevertheless possible (and assumed by EFT theory) that at least some of these clients subsequently reached assertive anger, which we can test in further studies involving later sessions in therapy.

Similarly, it was self-soothing rather than assertive anger which was associated with improvement on the overly accommodating subdomain. This also may reflect the benefit of changing focus to oneself from others. Indeed, self-soothing can be taken to be both agentic and implicitly self-assertive (Pascual-Leone \& Greenberg, 2005), since it involves recognizing one's true and valid needs. Thus, a person who becomes more capable of self-care may also begin to feel less needy, more capable of asserting him- or herself, and thus less accommodating in relationships. However, closer research on clients' life outside of therapy would be needed to confirm such interpretations.

\section{Methodological considerations}

This study has several strengths. First, emotional processing states during therapy were assessed with a measure that enables comprehensively assessing different emotional states, and takes into account both the cognitive and the affective aspects of experience. It has been specifically developed to assess psychotherapy processes and has been increasingly used in process-outcome research (Choi et al., 2016; Pascual-Leone \& Greenberg, 2007; Pascual-Leone, 2009, 2018). Second, the sessions were closely coded throughout for emotion-related content, providing a stronger detection of emotion effects than would have been possible by picking random samples from the sessions (Pos et al., 2009). Third, we used both patient- and observerrated measures which provided multiple observational perspectives on therapeutic processes, thereby lessening the subjective biases inherent in the use of only a single perspective (Orlinsky, Rønnestad, \& Willutzki, 2004). Fourth, the 18-month post-treatment follow-up enabled detecting 
effects evident only after the end of therapies, which is arguably of particular relevance in the case of interpersonal problems (Barkham et al., 1996; Howard et al., 1993).

The study also had some limitations. First and most obvious limitation is that the sample was relatively small, and consequently we reported and discussed all associations under $\mathrm{p}<.10$. While subtler effects may have been missed due to the sample size, we nevertheless reported large, virtually reliable effects. Further, while examining single correlations would be liable to produce some statistically significant chance findings due to multiple comparisons, evaluating the circumplex structure of emotional processing states provided further support for our hypotheses (Zimmermann \& Wright, 2017). Second, relatedly, the small number of therapists and patients per therapist precluded using multilevel modelling to meaningfully investigate therapist effects (Adelson \& Owen, 2012). Thirdly, as the study was based on those patients who filled the measures at all three time points, the results may not be generalizable to the patients lost in follow-up. Fourth, some CAMS categories are quite broad, some of which may also collapse important and distinctive experiences (e.g., different types of Hurt/Grief, Negative SelfEvaluations) that may be better parsed. Fifth, this being to our knowledge the first study to comprehensively investigate the relationship between the IIP and the CAMS, the study was to a degree exploratory; and the boundaries between interpersonal problems and emotional processing states may be perhaps unavoidably somewhat overlapping. Nevertheless, the found meaningful associations between relating in one's life and emotional processing during therapy can serve as an impetus for more nuanced studies.

\section{Clinical implications and directions for future research}

Rather than explore global change in interpersonal problems, this study is an initial investigation about how specific pre-treatment interpersonal problems of depressed patients 
change in psychotherapy. Such more specific investigations of subpopulations have long been called for (Horowitz et al., 1988; Horowitz, 2004), but are still relatively rare (Hames et al., 2014; McFarquhar et al., 2018). Via connecting interpersonal theory and research on emotionfocused therapy, this study begins to address these issues.

Insofar as verified, the present findings already have some practical implications. They contribute to an evidence-based "process map" for clinicians in conceptualizing which emotional states particular patients might struggle with and what adaptive emotions may be specifically beneficial for them (Timulak \& Pascual-Leone, 2015). As such, they may help therapists develop more nuanced case formulations based on the patients' interpersonal problems, observe where their patients are "at" during therapy, and plan interventions for moving them forward (PascualLeone \& Kramer, 2017).

However, there is an obvious need for future research to replicate and verify these findings in other samples. Larger patient and therapist samples, involving more rated sessions, would also enable addressing several issues. These would include i) forming reasonably-sized subgroups of patients with particular IIP profiles and investigating whether they evidence different change processes (cf. Cain et al., 2012; Clapp et al., 2014; Salzer et al., 2010); ii) studying the emotional processing sequences of recovered and unrecovered cases, including also earlier and later stages of therapy (cf. Choi \& Pos, 2016); and iii) employing multilevel modelling to investigate possible therapist effects, e.g. whether certain therapists appear more apt at facilitating transformational emotional processes (Atzil-Slonim et al., 2018; Kramer, PascualLeone, Rohde, \& Sachse, 2016; Pascual-Leone, 2018). Going beyond EFT, it is an interesting question whether the same associations would be observed in other psychotherapeutic models. Since EFT aims specifically to amplify emotion in the service of therapeutic outcomes, clients 
with similar interpersonal problems might be more muted in their reactions when engaged in other types of therapy. Further, using observer measures to assess clients' interpersonal behavior outside of therapy would provide a more comprehensive understanding of treatment effects.

\section{Conclusions}

Depressed clients who report different pre-treatment interpersonal problems are prone to different emotional processes during the working phase of therapy. Reduction of particular interpersonal problems appears to benefit from accessing and expressing different emotional processing states during the working phase of therapy.

Further studies should verify the findings in larger samples and investigate productive and unproductive emotional sequences. The results suggest that clients' needs for improving on their specific problems may be met by helpfully accessing emotion states important to those problems. If verified, the findings can inform individual case conceptualization and treatment planning to improve the outcomes of particular types of depressed clients. 


\section{References}

Adelson, J. L., \& Owen, J. (2012). Bringing the psychotherapist back: Basic concepts for reading articles examining therapist effects using multilevel modeling. Psychotherapy, 49, 152-162.

American Psychiatric Association (1987). Diagnostic and statistical manual of mental disorders (3rd ed.). Washington, DC: American Psychiatric Association.

Atzil-Slonim, D., Bar-Kalifa, E., Fisher, H., Peri, T., Lutz, W., Rubel, J., \& Rafaeli, E. (2018). Emotional congruence between clients and therapists and its effect on treatment outcome. Journal of Counseling Psychology, 65, 51-64.

Bakan, D. (1966). The duality of human existence: Isolation and communion in Western man. Boston: Beacon Press.

Barkham, M., Rees, A., Stiles, W. B., Shapiro, D. A., Hardy, G. E., \& Reynolds, S. (1996). Dose-effect relations in time-limited psychotherapy for depression. Journal of Consulting and Clinical Psychology, 64, 927-935.

Barrett, M. S., \& Barber, J. P. (2007). Interpersonal profiles in major depressive disorder. Journal of Clinical Psychology, 63, 247-266.

Barth, J., Munder, T., Gerger, H., Nüesch, E., Trelle, S., Znoj, H., Jüni, P. \& Cuijpers, P. (2016). Comparative efficacy of seven psychotherapeutic interventions for patients with depression: a network meta-analysis. Focus, 14, 229-243. 
Beck A. T. (1983). Cognitive therapy of depression: new perspectives. In P. Clayton \& J.E.

(Eds.), Treatment of Depression: Old Controversies and New Approaches (pp. 265-290). New York: Raven.

Beck, A. T., Steer, R. A., \& Garbin, M. G. (1988). Psychometric properties of the Beck Depression Inventory: Twenty-five years of evaluation. Clinical Psychology Review, 8, 77100.

Beck, A. T., Ward, C. H., Mendelsohn, M., Mock, J., \& Erbaugh, J. (1961). An inventory for measuring depression. Archives of General Psychiatry, 4, 561-571.

Becker, L. A. (2000, ). Effect size. Accessed on June 18, 2018 from https://www.uccs.edu/lbecker/effect-size.

Benjamin, L. S. (1974). Structural analysis of social behavior. Psychological Review, 81, 392425.

Benjamin, L. S. (1996). Interpersonal diagnosis and treatment of personality disorders (2nd ed.). New York, NY: Guilford.

Blatt, S. J., \& Zuroff, D. C. (1992). Interpersonal relatedness and self-definition: Two prototypes for depression. Clinical Psychology Review, 12, 527-562.

Blatt, S. J., Shahar, G., \& Zuroff, D. C. (2001). Anaclitic (sociotropic) and introjective (autonomous) dimensions. Psychotherapy: Theory, Research, Practice, Training, 38, 449454. 
Blatt, S. J., \& Shahar, G. (2004). Psychoanalysis-With whom, for what, and how? Comparisons with psychotherapy. Journal of the American Psychoanalytic Association, 52, 393-447.

Cain, N. M., Ansell, E. B., Wright, A. G. C., Hopwood, C. J., Thomas, K. M., Pinto, A., . . Grilo, C. M. (2012). Interpersonal pathoplasticity in the course of major depression. Journal of Consulting and Clinical Psychology, 80, 78-86.

Choi, B. H., Pos, A. E., \& Magnusson, M. S. (2016). Emotional change process in resolving selfcriticism during experiential treatment of depression. Psychotherapy Research, 26, 484-499. http://dx.doi.org/10.1080/10503307.2015.1041433

Clapp, J. D., Grubaugh, A. L., Allen, J. G., Oldham, J. M., Fowler, J. C., Hardesty, S., \& Frueh, B. C. (2014). Interpersonal change following intensive inpatient treatment. Psychiatry: Interpersonal \& Biological Processes, 77, 247-262.

Cuijpers, P., Karyotaki, E., Weitz, E., Andersson, G., Hollon, S. D., \& van Straten, A. (2014). The effects of psychotherapies for major depression in adults on remission, recovery and improvement: a meta-analysis. Journal of Affective Disorders, 159, 118-126.

Desmet, M., Vanheule, S., Groenvynck, H., Verhaeghe, P., Vogel, J., \& Bogaerts, S. (2007). The depressive experiences questionnaire. European Journal of Psychological Assessment, 23, $89-98$.

Dinger, U., Barrett, M. S., Zimmermann, J., Schauenburg, H., Wright, A. G., Renner, F., ... \& Barber, J. P. (2015). Interpersonal problems, dependency, and self-criticism in major depressive disorder. Journal of Clinical Psychology, 71, 93-104. 
Elliott, R., Slatick, E., \& Urman, M. (2001). Qualitative change process research on psychotherapy: Alternative strategies. Psychologische Beitrage, 43, 69-111.

Elliott, R., Watson, J. C., Goldman, R. N., \& Greenberg, L. S. (2004). Learning emotion-focused therapy: The process-experiential approach to change. Washington, DC: American Psychological Association.

Ellison, J. A., Greenberg, L. S., Goldman, R. N., \& Angus, L. (2009). Maintenance of gains following experiential therapies for depression. Journal of Consulting and Clinical Psychology, 77, 103-112.

Frank, J. D., \& Frank, J. B. (1991). Persuasion and healing: a comparative study of psychotherapy (3rd ed.). Baltimore: Johns Hopkins University Press.

Goldman, R. N., Greenberg, L. S., \& Angus, L. (2006). The effects of adding emotion-focused interventions to the client-centered relationship conditions in the treatment of depression. Psychotherapy Research, 16, 536-546.

Greenberg, L. S., Rice, L., \& Elliott, R. K. (1993). Facilitating emotional change: The momentby-moment process. New York, NY: Guilford.

Greenberg, L. S. \& Safran, J. D. (1991). Emotion, psychotherapy, and change. New York, NY: Guildford.

Greenberg, L. S., \& Watson, J. C. (2006). Emotion-focused therapy for depression. Washington, DC: American Psychological Association. 
Greenberg, L. S. (2004). Emotion-focused therapy. Clinical Psychology \& Psychotherapy, 11, 316.

Greenberg, L. S. (2002). Emotion-focused therapy: Coaching clients to work through their feelings. Washington, DC: American Psychological Association.

Greenberg, L. S., \& Watson, J. (1998). Experiential therapy of depression: Differential effects of client-centered relationship conditions and process experiential interventions. Psychotherapy Research, 8, 210-224.

Grosse Holtforth, M., Krieger, T., Zimmermann, J., Altenstein-Yamanaka, D., Dörig, N., Meisch, L., \& Hayes, A. M. (2019). A randomized-controlled trial of cognitive-behavioral therapy for depression with integrated techniques from emotion-focused and exposure therapies. Psychotherapy Research, 29, 30-44.

Grosse Holtforth, M., Lutz, W., \& Grawe, K. (2006). Structure and Change of the IIP-D Pre-and Post-psychotherapy. European Journal of Psychological Assessment, 22, 98-103.

Grosse Holtforth, M., Pincus, A. L., Grawe, K., Mauler, B., \& Castonguay, L. G. (2007). When what you want is not what you get: Motivational correlates of interpersonal problems in clinical and nonclinical samples. Journal of Social and Clinical Psychology, 26, 1095-1119.

Gurtman, M. B. (1992). Construct validity of interpersonal personality measures: The interpersonal circumplex as a nomological net. Journal of Personality and Social Psychology, 63, 105-118. 
Gurtman, M. B., \& Pincus, A. L. (2003). The circumplex model: Methods and research applications. In J. Schinka \& W. Velicer (Eds.), Comprehensive handbook of psychology, Vol. 2: Research methods in psychology (pp. 407-428). New York, NY: Wiley

Haase, M., Frommer, J., Franke, G. H., Hoffmann, T., Schulze-Muetzel, J., Jäger, S., ... \& Schmitz, N. (2008). From symptom relief to interpersonal change: Treatment outcome and effectiveness in inpatient psychotherapy. Psychotherapy Research, 18, 615-624.

Hames, J. L., Hagan, C. R., \& Joiner, T. E. (2013). Interpersonal processes in depression. Annual Review of Clinical Psychology, 9, 355-377.

Heinonen, E., Knekt, P., Harkanen, T., Virtala, E., \& Lindfors, O. (2018). Associations of early childhood adversities with mental disorders, psychological functioning, and suitability for psychotherapy in adulthood. Psychiatry Research, 264, 366-373.

Hopwood, C. J., Zimmermann, J., Pincus, A. L., \& Krueger, R. F. (2015). Connecting personality structure and dynamics: Towards a more evidence-based and clinically useful diagnostic scheme. Journal of Personality Disorders, 29, 431-448.

Horowitz, L. M., Alden, L. E., Wiggins, J. S., \& Pincus, A. L. (2000). Inventory of interpersonal problems. London: Psychological Corporation.

Horowitz, L. M., Rosenberg, S. E., Baer, B. A., Ureno, G., \& Villasenor, V. S. (1988). Inventory of interpersonal problems: Psychometric properties and clinical applications. Journal of Consulting and Clinical Psychology, 56, 885-892. 
Horowitz, L. M. (2004). Interpersonal foundations of psychopathology. Washington, DC: American Psychological Association.

Howard, K. I., Lueger, R. J., Maling, M. S., \& Martinovich, Z. (1993). A phase model of psychotherapy outcome: Causal mediation of change. Journal of Consulting and Clinical Psychology, 61, 678-685.

Huber, D., Henrich, G., \& Klug, G. (2007). The Inventory of Interpersonal Problems (IIP): sensitivity to change. Psychotherapy Research, 17, 474-481.

Kiesler, D. J., Schmidt, J. A., \& Wagner, C. C. (1997). A circumplex inventory of impact messages: An operational bridge between emotion and interpersonal behavior. In R. Plutchik and H. R. Conte (Eds.), Circumplex Models of Personality and Emotions (pp. 221244). Washington, DC: American Psychological Association.

Korman, L. M. (1991). Emotion episodes. Unpublished master's thesis, York University, Toronto, Ontario, Canada.

Kramer, U., Pascual-Leone, A., Rohde, C., \& Sachse, R. (2016). Emotional processing, interaction process, and outcome in clarification- oriented psychotherapy for personality disorders: A process-outcome analysis. Journal of Personality Disorders, 30, 373-394.

Lane, R. D., Ryan, L., Nadel, L., \& Greenberg, L. (2015). Memory reconsolidation, emotional arousal, and the process of change in psychotherapy: New insights from brain science. Behavioral and Brain Sciences, 38. 
Leary, T. (1957). Interpersonal diagnosis of personality: a functional theory and methodology for personality evaluation. Oxford: Rona Press.

Leichsenring, F., Biskup, J., Kreische, R., \& Staats, H. (2005). The Güttingen study of psychoanalytic therapy: First results. International Journal of Psychoanalysis, 86, 433-455.

Llewelyn, S. (1988). Psychological therapy as viewed by clients and therapists. British Journal of Clinical Psychology, 27, 223-238.

McFarquhar, T., Luyten, P., \& Fonagy, P. (2018). Changes in interpersonal problems in the psychotherapeutic treatment of depression as measured by the inventory of interpersonal problems: A systematic review and meta-analysis. Journal of Affective Disorders, 226, 108123.

O'Brien, T. B., \& DeLongis, A. (1996). The interactional context of problem-, emotion-, and relationship-focused coping: the role of the Big Five personality factors. Journal of Personality, 64, 775-813.

Orlinsky, D. E. \& Howard, K. I. (1975). Varieties of psychotherapeutic experience. New York: Teacher's College Press.

Orlinsky, D. E., Rønnestad, M. H., \& Willutzki, U. (2004). Fifty years of psychotherapy processoutcome research: Continuity and change. In M. J. Lambert (Ed.), Bergin and Garfield's handbook of psychotherapy and behavior change (5th ed., pp. 307-393). New York: Wiley.

Pascual-Leone, A. (2009). Dynamic emotional processing in experiential therapy: Two steps forward, one step back. Journal of Consulting and Clinical Psychology, 77, 113-126. 
Pascual-Leone, A. (2018). How clients “change emotion with emotion”: A programme of research on emotional processing. Psychotherapy Research, 28, 165-182.

Pascual-Leone, A., \& Greenberg, L. (2005). Classification of Affective-Meaning States (CAMS). In A. Pascual--Leone, Emotional processing in the therapeutic hour: Why the only way out is through (pp. 289-367). Unpublished doctoral thesis, York University, Toronto, Ontario, Canada.

Pascual-Leone, A., \& Greenberg, L. S. (2007). Emotional processing in experiential therapy: Why "the only way out is through". Journal of Consulting and Clinical Psychology, 75, $875-887$.

Pascual-Leone, A., \& Kramer, U. (2017). Developing emotion-based case formulations: A research-informed method. Clinical Psychology \& Psychotherapy, 24, 212-225.

Pincus, A. L., \& Ansell, E. B. (2003). Interpersonal theory of personality. Handbook of psychology: Personality and social psychology, 5, 209-229.

Pincus, A. L., Cain, N. M., \& Wright, A. G. (2014). Narcissistic grandiosity and narcissistic vulnerability in psychotherapy. Personality Disorders: Theory, Research, and Treatment, 5, 439-443.

Pos, A. E. (2006). Experiential treatment for depression: A test of the experiential theory of change, differential effectiveness, and predictors of maintenance of gains. Unpublished doctoral thesis, York University, Toronto, Ontario, Canada. 
Pos, A. E., \& Paolone, D. A. (in press). Emotion-focused therapy for personality disorders. In L. S. Greenberg, \& R. Goldman (Eds.), Handbook of emotion-focused therapy. Washington, DC: American Psychological Association.

Pos, A. E., Greenberg, L. S., \& Warwar, S. H. (2009). Testing a model of change in the experiential treatment of depression. Journal of Consulting and Clinical Psychology, 77, 1055-1066.

Roche, M. J., Pincus, A. L., Lukowitsky, M. R., Ménard, K. S., \& Conroy, D. E. (2013). An integrative approach to the assessment of narcissism. Journal of Personality Assessment, 95, 237-248.

Rothman, K. J., Greenland, S., \& Lash, T. L. (2008). Modern epidemiology (Vol. 3). Philadelphia: Wolters Kluwer Health/Lippincott Williams \& Wilkins.

Sadikaj, G., Moskowitz, D. S., Russell, J. J., \& Zuroff, D. C. (2015). Submissiveness in social anxiety disorder: the role of interpersonal perception and embarrassment. Journal of Social and Clinical Psychology, 34, 1-27.

Salzer, S., Leibing, E., Jakobsen, T., Rudolf, G., Brockmann, J., Eckert, J., ... \& Keller, W. (2010). Patterns of interpersonal problems and their improvement in depressive and anxious patients treated with psychoanalytic therapy. Bulletin of the Menninger Clinic, 74, 283-300.

Szklo, M., \& Nieto, F. J. (2014). Epidemiology: beyond the basics. Jones \& Bartlett Publishers.

Speed, B. C., Goldstein, B. L., \& Goldfried, M. R. (2018). Assertiveness training: A forgotten evidence-based treatment. Clinical Psychology: Science and Practice, 25, e12216. 
Spitzer, R., Williams, J., Gibon, M., \& First, M. (1989). Structured clinical interview for the DSM-III-R. New York, NY: New York State Psychiatric Institute.

Streiner, D. L., \& Norman, G. R. (2011). Correction for multiple testing: Is there a resolution? Chest, 140, 16-18.

Sullivan, H. S. (1953). The interpersonal theory of psychiatry. New York: Norton.

Teasdale, J. D. (1999). Emotional processing, three modes of mind and the prevention of relapse in depression. Behaviour Research and Therapy, 37(Suppl 1), S53-S77.

Thompson, K., D’iuso, D., Schwartzman, D., Dobson, K. S., \& Drapeau, M. (2018). Changes in depressed patients' self-statements. Psychotherapy Research, 1-13.

Timulak, L., \& Pascual-Leone, A. (2015). Contribution to case conceptualisation in emotionfocused therapy. Clinical Psychology and Psychotherapy, 22, 619-636.

Wang, S., Roche, M. J., Pincus, A. L., Conroy, D. E., Rebar, A. L., \& Ram, N. (2014). Interpersonal dependency and emotion in every day life. Journal of Research in Personality, 53, 5-12.

Watson, J. C., Gordon, L. B., Stermac, L., Kalogerakos, F., \& Steckley, P. (2003). Comparing the effectiveness of process-experiential with cognitive-behavioral psychotherapy in the treatment of depression. Journal of Consulting and Clinical Psychology, 71, 773-781.

Werbart, A., Hägertz, M., \& Ölander, N. B. (in press). Matching patient and therapist anacliticintrojective personality configurations matters for psychotherapy outcomes. Journal of Contemporary Psychotherapy. 
Whelton, W. J., \& Greenberg, L. S. (2005). Emotion in self-criticism. Personality and Individual Differences, 38, 1583-1595.

Widiger, T. A., \& Smith, G. T. (2008). Personality and psychopathology. In O. P. John, R. W. Robins, \& L. A. Pervin (Eds.), Handbook of personality: Theory and research (3rd ed., pp. 743-769). New York: Guilford Press

Wong, K. (2016). Examining processes of change for experientially distant and experientially engaged client subgroups in experiential therapy for depression. Unpublished doctoral thesis, York University, Toronto, Ontario, Canada.

Wright, A. G. C., Pincus, A. L., Conroy, D. E., \& Hilsenroth, M. J. (2009). Integrating methods to optimize circumplex description and comparison of groups. Journal of Personality Assessment, 91, 311-322.

Wright, A. G., Pincus, A. L., Hopwood, C. J., Thomas, K. M., Markon, K. E., \& Krueger, R. F. (2012). An interpersonal analysis of pathological personality traits in DSM-5. Assessment, $19,263-275$.

Zimmermann, J., \& Wright, A. G. (2017). Beyond description in interpersonal construct validation: Methodological advances in the circumplex structural summary approach. Assessment, 24, 3-23. 
Table 1

Patient Baseline Characteristics $(n=23)$

Sociodemographic factors

Mean (SD)

Age (years)

$40.7(9.0)$

Gender ( $\%$ female)

60.9

Education (some college or higher education) (\%) 60.9

Marital status (never married) (\%)

29.4 
Table 2

Mean Prevalence $(S D)^{a}$ of Emotional Processing States During the Two Most Helpful Sessions of Therapy $(n=23)$ Maladaptive

Rejecting anger $.115(.125)$

Fear and shame

Negative self-evaluation

Adaptive

Needs

Hurt and grief .077 (.091)

Assertive anger .085 (.083)

Self-soothing

$.014(.028)$

${ }^{a}$ Proportion of particular emotional processing states out of the total number of emotion episodes. 
Table 3

Mean Sum (SD) of Interpersonal Problems from Pre-Treatment to Post-Treatment and 18-months' Follow-Up $(n=23)$

\begin{tabular}{|c|c|c|c|c|c|c|}
\hline $\begin{array}{l}\text { Interpersonal } \\
\text { problem domains }\end{array}$ & $\begin{array}{l}\text { Pre- } \\
\text { treatment }\end{array}$ & $\begin{array}{l}\text { Post- } \\
\text { treatment }\end{array}$ & $\begin{array}{l}\text { 18-month } \\
\text { follow-up }\end{array}$ & $\begin{array}{l}\text { Effect size }(d) \\
\text { between post-and } \\
\text { pre-treatment }\end{array}$ & $\begin{array}{l}\text { Effect size }(d) \text { between } \\
\text { 18-months' follow-up } \\
\text { and pre-treatment }\end{array}$ & $\begin{array}{l}p \text { for change } \\
\text { across time }\end{array}$ \\
\hline Domineering ${ }^{\mathrm{a}}$ & $5.91(4.38)$ & $3.77(3.60)$ & $4.83(3.82)$ & 0.53 & 0.26 & $.01 *$ \\
\hline Vindictive $^{a}$ & $6.30(4.77)$ & $5.45(4.38)$ & $5.52(4.86)$ & 0.19 & 0.16 & .77 \\
\hline Cold $^{\mathrm{a}}$ & $8.96(5.29)$ & $6.05(5.01)$ & $7.13(4.99)$ & 0.56 & 0.35 & .12 \\
\hline $\begin{array}{l}\text { Socially } \\
\text { inhibited }^{\mathrm{a}}\end{array}$ & $11.5(7.05)$ & $7.05(6.39)$ & $7.83(7.90)$ & 0.66 & 0.49 & $.02 *$ \\
\hline Nonassertive $^{\mathrm{a}}$ & $16.0(6.34)$ & $12.3(7.99)$ & $11.5(7.22)$ & 0.51 & 0.66 & $.03^{*}$ \\
\hline $\begin{array}{l}\text { Overly } \\
\text { accommodating }{ }^{\mathrm{a}}\end{array}$ & $12.0(5.24)$ & $9.91(7.37)$ & $9.30(6.12)$ & 0.33 & 0.47 & .14 \\
\hline Self-sacrificing ${ }^{\mathrm{a}}$ & $14.5(4.85)$ & $10.8(6.88)$ & $11.0(6.20)$ & 0.62 & 0.62 & $.01 *$ \\
\hline Intrusive $^{\mathrm{a}}$ & $8.21(4.88)$ & $5.77(5.34)$ & $5.70(5.69)$ & 0.48 & 0.47 & $.03^{*}$ \\
\hline Total $^{\mathrm{b}}$ & $83.4(30.3)$ & $61.0(37.1)$ & $62.8(34.5)$ & 0.66 & 0.63 & $<.001 * *$ \\
\hline
\end{tabular}

$* \mathrm{p}<.05 ; * * \mathrm{p}<.01$

${ }^{\text {a }}$ Potential range $0-32$.

${ }^{\mathrm{b}}$ Potential range 0-256. 
Table 4

Associations of Pre-treatment Interpersonal Problems with Maladaptive Emotional Processing States in the Two Most Helpful Sessions of Therapy $(n=23)^{\text {a }}$

\begin{tabular}{llll}
\hline & & \multicolumn{2}{l}{ Emotional Processing States } \\
\hline Pre-treatment interpersonal problems & Rejecting anger & Fear and shame & Negative self-evaluation \\
\hline Domineering & .227 & -.248 & .261 \\
Vindictive & .306 & .031 & $.402 \dagger$ \\
Cold & -.044 & .314 & $.446^{*}$ \\
Socially inhibited & -.110 & $.547^{* *}$ & $.368 \dagger$. \\
Nonassertive & -.205 & .310 & $.508^{*}$ \\
Overly accommodating & -.112 & .113 & $.524^{*}$ \\
Self-sacrificing & .019 & .164 & $.506^{*}$ \\
Intrusive & .182 & -.123 & .349 \\
Total interpersonal distress & .018 & .242 & $.598^{* *}$ \\
Elevation & & & .421 \\
Amplitude & 0.033 & 0.139 & \\
Angular displacement & 0.234 & 0.307 & \\
Goodness of fit $\left(\mathrm{R}^{2}\right)$ & $91.6^{\circ}$ & $242.6^{\circ}$ & \\
\hline
\end{tabular}

$\dagger \mathrm{p}<.10 ; * \mathrm{p}<.05 ; * * \mathrm{p}<.01$

${ }^{a}$ Pearson correlations. 
Table 5

Associations of Adaptive Emotional Processing States During Therapy with Improvement in Interpersonal Problems at 18 Months' Follow-Up $(n=23)^{\mathrm{a}}$

\begin{tabular}{lllll}
\hline & \multicolumn{4}{c}{ Emotional Processing States } \\
\cline { 2 - 5 } $\begin{array}{l}\text { Residual gain scores in inter- } \\
\text { personal problem domains }{ }^{\mathrm{b}}\end{array}$ & Needs & Hurt and grief & Assertive anger & Self-soothing \\
\hline Dominant & -.164 & -.102 & $-.424^{*}$ & .078 \\
Vindictive & .308 & -.148 & -.303 & .078 \\
Cold & .142 & .096 & -.056 & -.055 \\
Socially inhibited & .146 & $-.363 \dagger$ & -.266 & -.151 \\
Nonassertive & -.127 & $-.421^{*}$ & -.220 & -.202 \\
Overly accommodating & -.076 & $-.440^{*}$ & -.293 & $-.397 \dagger$ \\
Self-sacrificing & -.103 & $-.429 *$ & $-.374 \dagger$ & -.295 \\
Intrusive & -.086 & .086 & -.296 & -.216 \\
Total interpersonal distress & .018 & -.304 & $-.378 \dagger$ & -.216 \\
& & & & \\
\hline
\end{tabular}

$\uparrow \mathrm{p}<.10 ; * \mathrm{p}<.05 ; * * \mathrm{p}<.01$

a Pearson correlations.

${ }^{\mathrm{b}}$ Negative scores indicate improvement on interpersonal problem domains. 
Figure 1. A Taxonomy of Interpersonal Problems (cf. Horowitz, 2004). Adapted from "Construction of Circumplex Scales for the Inventory of Interpersonal Problems" by L. E. Alden, J. S. Wiggins, and A. L. Pincus, 1990, p. 529, Journal of Personality Assessment, 55, 521-536. Copyright 1990 by the Society of Personality Assessment.

Domineering/Controlling $\left(90^{\circ}\right)$

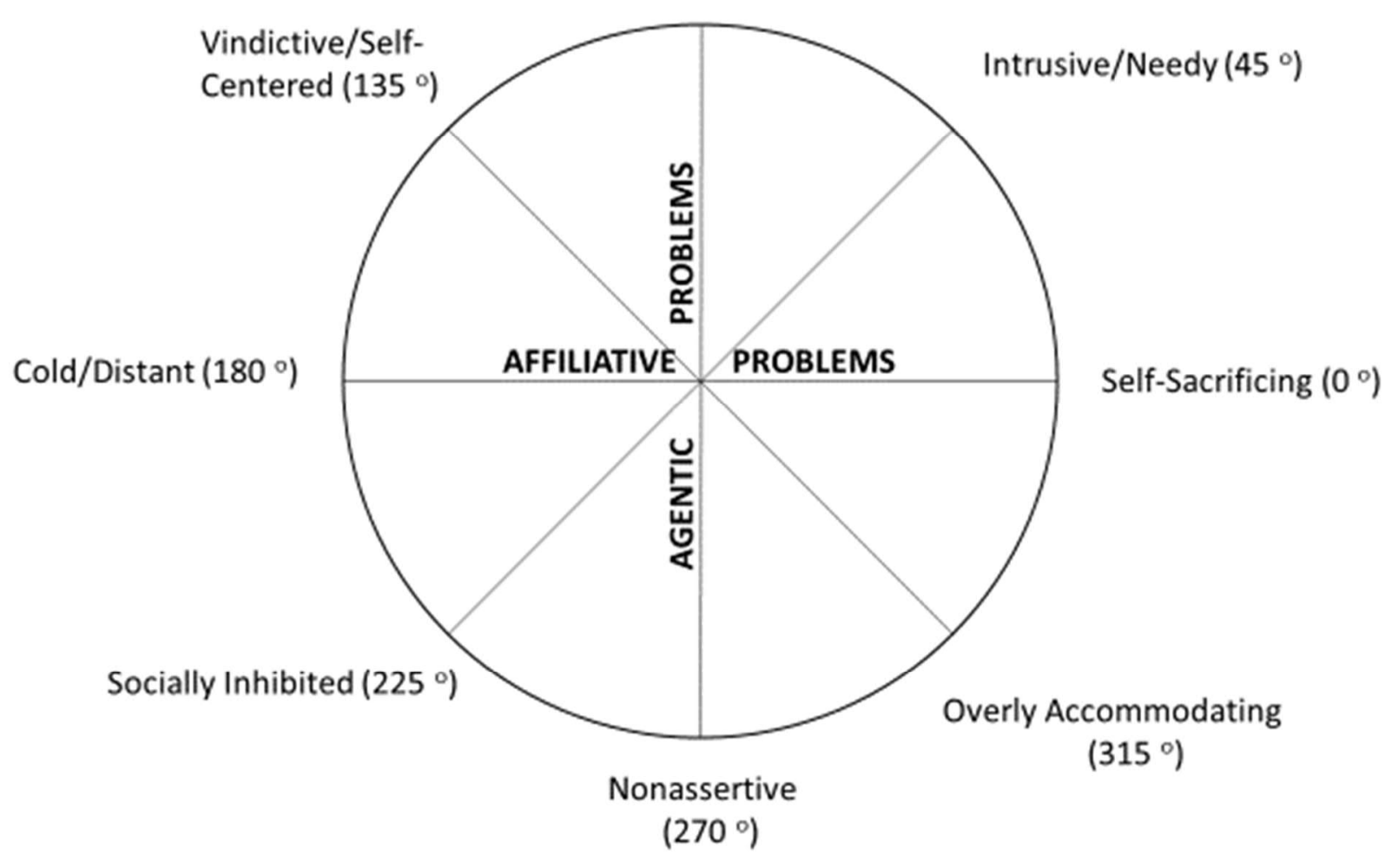

